\title{
Nitrogen diffusion in nitrogen-doped yttria stabilised zirconia $\dagger$
}

\author{
Martin Kilo, ${ }^{* a}$ Marcela A. Taylor,$\ddagger^{a}$ Christos Argirusis, ${ }^{a}$ Günter Borchardt, ${ }^{a}$ Martin Lerch, ${ }^{b}$ \\ Odile Kaïtasov $^{c}$ and Bernard Lesage ${ }^{d}$ \\ a TU Clausthal, Institut für Metallurgie, Robert-Koch-Straße 42, D-38678 Clausthal-Zellerfeld, \\ Germany. E-mail: martin.kilo@tu-clausthal.de \\ ${ }^{b}$ TU Berlin, Institut für Chemie/Sekr. C2, Straße des 17. Juni 135, D-10623 Berlin, Germany \\ ${ }^{c}$ L.E.M.H.E., Bât. 410, Université Paris-Sud Orsay, F-91405 Orsay-Cedex, France \\ ${ }^{d}$ C.S.N.S.M., Bât. 410, Université Paris-Sud Orsay, F-91405 Orsay-Cedex, France
}

Received 24th November 2003, Accepted 16th March 2004

First published as an Advance Article on the web

\begin{abstract}
Nitrogen self-diffusion was measured in single crystalline nitrogen-doped yttria-stabilised zirconia (YZrON) containing $10 \mathrm{~mol} \%$ yttrium oxide. Samples containing two different nitrogen contents $(5$ and $6 \mathrm{~mol} \% \mathrm{~N}$ on the anion sublattice) were investigated as a function of temperature $(650-1000 \mathrm{~K})$ using implanted ${ }^{15} \mathrm{~N}$ as a stable tracer. For a given temperature, the nitrogen diffusivity was nearly independent of the nitrogen content in the nitrogen-doped yttria-stabilised zirconia, which can be only partially understood using defect chemistry. The activation enthalpy of nitrogen diffusion was between 2 and $2.5 \mathrm{eV}$ with a preexponential factor of the order of $10^{0} \mathrm{~cm}^{2} \mathrm{~s}^{-1}$, which corresponds to a migration entropy of $5 k_{\mathrm{B}}$. The surface exchange reaction between nitrogen and the oxonitride surface was investigated at $1073 \mathrm{~K}$ using 200 mbar gaseous ${ }^{15} \mathrm{~N}_{2}$ and was found to be slow but considerable. Decreasing the oxygen content in the gas phase can enhance the nitrogen incorporation into the oxonitrides.
\end{abstract}

\section{Introduction}

It is widely known that cubic stabilised zirconia can be obtained by the addition of lower valent oxides like yttria or calcia to zirconia (leading to YSZ or CSZ, respectively). These materials exhibit a very high ionic conductivity due to their inherently high concentration of oxygen vacancies, which are formed because of the addition of the oxides (see eqn. (1), for the incorporation of $\left.\mathrm{Y}_{2} \mathrm{O}_{3}\right){ }^{1}$

$$
\mathrm{Y}_{2} \mathrm{O}_{3}+2 \mathrm{Zr}_{\mathrm{Zr}}^{x}+\mathrm{O}_{\mathrm{O}}^{x} \rightarrow 2 \mathrm{Y}_{\mathrm{Zr}}^{\prime}+\mathrm{V}_{\mathrm{O}}^{2 \cdot}+2 \mathrm{ZrO}_{2}
$$

An alternative way to increase the concentration of oxygen vacancies on the anion lattice is the addition of higher valent anions in the stabilised zirconias leading to metal-zirconium (yttrium) oxonitrides, e.g. $\quad(\mathrm{Y}, \mathrm{Zr})-(\mathrm{O}, \mathrm{N}), \quad(\mathrm{Mg}, \mathrm{Zr})-(\mathrm{O}, \mathrm{N})$, $(\mathrm{Sc}, \mathrm{Zr})-(\mathrm{O}, \mathrm{N})$ or $(\mathrm{Ca}, \mathrm{Zr})-(\mathrm{O}, \mathrm{N})$. It was recently shown that the incorporation of a few $\mathrm{mol} \%$ nitrogen into YSZ increases the ionic conductivity by a factor of 3 , more than would be expected by using simple defect chemistry assuming that the conductivity increase is directly related to an enhanced number of anion vacancies formed according to eqn. (2), ${ }^{2,3}$

$$
\mathrm{N}_{2}+3 \mathrm{O}_{\mathrm{O}}^{x} \rightarrow 2 \mathrm{~N}_{\mathrm{O}}^{\prime}+\mathrm{V}_{\mathrm{O}}^{2 \bullet}+\frac{1}{2} \mathrm{O}_{2}
$$

It is suspected that the increased ionic conductivity might be at least partially due to an enhanced transport of nitrogen. Furthermore, zirconium oxonitride has a very high mechanical stability making it also a very attractive material for structural applications. ${ }^{4}$ Unfortunately, the ionic conductivity seems to decrease with time, which was attributed to an effect of ordering: doped zirconium oxonitrides show a strong tendency to form long-range ordered rhombohedral phases, whose

† Presented at the 85th International Bunsen Colloquium on "Atomic Transport in Solids: Theory and Experiments" Rauischholzhausen, Germany, October 31, 2003.

$\ddagger$ On leave from University of La Plata, IFLP, CONICET Argentina. Member of Carrera del Investigador Científico CONICET Argentina. structure is not fully understood. In scandia-stabilised zirconia (ScSZ), a similar class of anion ordered rhombohedral phases were observed, which reduced the oxygen conductivity significantly, ${ }^{5}$ thus making it likely to observe a similar effect on rhombohedral phases formed by nitrogen doping.

In a thermodynamics study, Molodetsky et al. ${ }^{6}$ have shown that the nitrogen vacancy formation enthalpy in yttrium oxonitride is $190 \mathrm{~kJ} \mathrm{~mol}^{-1}$, about twice the value of the oxygen vacancy formation enthalpy in stabilised oxides. ${ }^{7}$ This difference should be responsible for the formation of anion-ordered phases.

The nitrogen transport in oxonitrides itself has never been characterised by direct methods. There are only a few indirect investigations: using some qualitative estimations, Lerch $^{8}$ suggested from the nitrogen uptake kinetics into pure zirconia that nitrogen diffusion might be 3 orders of magnitude slower than oxygen diffusion at $1400 \mathrm{~K}\left(\sim 10^{-9} \mathrm{~cm}^{2} \mathrm{~s}^{-1}\right)$. Recently, Deghenghi et al. ${ }^{9}$ and Chung et al. ${ }^{10}$ investigated the reaction of polycrystalline tetragonal YSZ containing $3 \mathrm{~mol} \%$ yttria with nitrogen at elevated temperatures $\left(1400\right.$ to $\left.1600^{\circ} \mathrm{C}\right)$. They used local Raman spectroscopy and transmission optical microscopy to investigate the migration of the moving reaction front for the formation of the oxonitrides in a pure nitrogen atmosphere. Assuming the uptake reaction to be limited by the diffusion of nitrogen in the growing oxonitride layer, the two groups found activation enthalpies for the nitrogen diffusion of $1.76 \mathrm{eV}$ with preexponential factors of $3.98 \times 10^{-3} \mathrm{~cm}^{2}$ $\mathrm{s}^{-1}, 9$ or $1.92 \mathrm{eV}$ and $7.5 \times 10^{-2} \mathrm{~cm}^{2} \mathrm{~s}^{-1},{ }^{10}$ respectively.

In the present paper, we give results for the first direct measurement of the nitrogen diffusion in single crystalline yttriumdoped zirconium oxonitride of different nitrogen content using the stable isotope ${ }^{15} \mathrm{~N}$.

\section{Experimental}

Samples

Cubic single crystals (oriented along the [100] axis) containing $10 \mathrm{~mol}^{\%} \mathrm{Y}_{2} \mathrm{O}_{3}$ (Zirmat, North Billerica, USA), were heated at 
temperatures of 1850 or $2000^{\circ} \mathrm{C}$ for $2 \mathrm{~h}$ in a carbon furnace under 1 bar of nitrogen atmosphere. After nitriding, the samples were black and opaque, with a partly pale yellow surface due to the formation of a thin $\mathrm{ZrN}$ layer. The nitrided samples were cut into slabs of appropriate size $\left(c a .10 \times 5 \times 0.5 \mathrm{~mm}^{3}\right)$, ground and polished with the alumina suspension Final ${ }^{(i x}$ (particle size: $500 \mathrm{~nm}$ ). Thereafter, the samples were completely black; all originally formed $\mathrm{ZrN}$ was removed. Single-crystal XRD analysis confirmed that the samples still remained in a single crystalline state. The bulk nitrogen content, as measured using hot gas extraction, was 1.32 and $1.55 \mathrm{wt} . \%$, respectively. The conditions of the sample preparation and the nominal nitrogen sample compositions are summarized in Table 1.

Both types of samples were then implanted with an ion dose of $3 \times 10^{16} \mathrm{~cm}^{-2}$ with ${ }^{15} \mathrm{~N}$, starting from natural nitrogen gas. The implantation energy was $30 \mathrm{keV}$, this corresponds to an implantation depth of $40 \mathrm{~nm}$, as calculated by using the TRIM program, ${ }^{11}$ which was later confirmed by SIMS. After implantation, samples were cut in small slices of about $5 \times 5 \times 0.5$ $\mathrm{mm}^{3}$ and then used for diffusion anneals. For each diffusion experiment, one newly prepared sample was used.

\section{Nitrogen diffusion}

Diffusion anneals were performed for appropriate times at temperatures between 650 and $1200 \mathrm{~K}$ under vacuum in a stainless-steel apparatus fitted with CF flanges and a quartz tube (dynamically pumping: turbomolecular pump, base pressure $p<10^{-7}$ mbar). The samples were kept outside the hot zone of the furnace on a sample holder, which allows the measurement of the sample temperature. To start the experiments, the samples were moved quickly into the hot zone of the furnace. The sample temperature was continuously monitored during the experiments, and it was found that it took at least 2 min until the sample was at constant (equilibrium) temperature. After finishing the experiments, the sample was removed from the hot zone of the furnace and it was observed that the temperature dropped by $200^{\circ}$ within less than $1 \mathrm{~min}$, after which time the nitrogen diffusion was practically stopped. After completely cooling down the system, the turbomolecular pump was stopped, and air was admitted to the furnace to remove the samples; this procedure prevents oxidation of the samples.

Furthermore, nitrogen surface exchange reaction experiments were performed at $800^{\circ} \mathrm{C}$ by heating the samples prepared at $18500^{\circ} \mathrm{C}$ and $2000^{\circ} \mathrm{C}$ for 5 to $30 \mathrm{~min}$ in an atmosphere of ${ }^{15} \mathrm{~N}_{2}$, isotopically enriched to $>98 \%$ (Chemotrade, Leipzig/Germany; nominal oxygen content less than $0.1 \%$ ). The samples were heated in the same apparatus as described above under vacuum to $800^{\circ} \mathrm{C}$ and were allowed to equilibrate for some time. Thereafter, the valve to the turbomolecular pump was closed, and 200 mbar of ${ }^{15} \mathrm{~N}_{2}$ were added. This procedure only induced a moderate change of the temperature. After the experiment, the samples were transferred to the cold part of the furnace, and after cooling down, the nitrogen gas was recovered by freezing with liquid nitrogen. In order to prevent reaction with the remaining oxygen,

Table 1 Sample preparation conditions and resulting nitrogen content for the investigated samples ${ }^{a}$

\begin{tabular}{lllll}
\hline $\begin{array}{l}\text { Sample } \\
\text { name }\end{array}$ & $\begin{array}{l}\text { Annealing } \\
\text { time } / \mathrm{h}\end{array}$ & $T /{ }^{\circ} \mathrm{C}$ & $\begin{array}{l}\mathrm{N} \text { content } \\
(\text { wt. } \%)\end{array}$ & $\begin{array}{l}\mathrm{N} \text { anion site } \\
\text { occupancy }(\%)^{a}\end{array}$ \\
\hline YZrON-18 & 2 & 1850 & 1.32 & 5.3 \\
YZrON-20 & 2 & 2000 & 1.55 & 6.1
\end{tabular}

${ }^{a}$ For calculating the $\mathrm{N}$ anion site occupancy, it was assumed that nitrogen uptake was compensated with formation of oxygen vacancies according to eqn. (2). samples were covered in powder beds made of carbon powder or titanium powder, respectively, or were heated in the pure ${ }^{15} \mathrm{~N}_{2}$ atmosphere.

The depth distribution of the stable tracer ${ }^{15} \mathrm{~N}$ was measured either using a Cameca IMS $3 \mathrm{f}$ or using the VG SIMS-Lab at the École des Mines, Nancy. In the first case, the sample was sputtered with $10 \mathrm{kV} \mathrm{O}^{-}$and positively charged particles were measured, while in the latter case, the sample was sputtered with $7 \mathrm{kV} \mathrm{Ar}^{+}$and negatively charged sputtered particles were detected. Besides the masses of the nitrogen isotopes themselves $(m / z=14$ and $15 \mathrm{amu})$, the masses of the clusters ${ }^{14 / 15} \mathrm{~N}^{16} \mathrm{O}$ and ${ }^{14 / 15} \mathrm{~N}^{14} \mathrm{~N}$ were also monitored $(\mathrm{m} / \mathrm{z}=30$ and $31 \mathrm{amu}$, or 28 and $29 \mathrm{amu}$ ), which were found to have higher signal intensities than the base nitrogen isotopes on both machines in both measurement modes. For the positive SIMS mode, i.e. when positively charged secondary particles were analysed, we found some serious interferences at the mass 30 between the signal arising from ${ }^{14} \mathrm{~N}^{16} \mathrm{O}$ with signals due to silicon ${ }^{30} \mathrm{Si}$ : natural abundance $3.1 \%$; silicon ions have a very high sensitivity in the positive SIMS mode) being present as a tracer in the original and nitrided zirconia samples.

For the implanted samples, the fast nitrogen diffusion leads to diffusion profiles that quickly flatten out since the amount of diffusing nitrogen is limited by the amount of implanted ${ }^{15} \mathrm{~N}$. Since the heating-up time was at least $2 \mathrm{~min}$, we were not able to go much beyond $1000 \mathrm{~K}$ for the temperature of the diffusion experiments and still get useable profiles.

Tracer diffusivities $D$ were determined by fitting appropriate solutions of Fick's second law ${ }^{12}$ to the tracer isotope concentration profile. Eqn. (3) was used to describe nitrogen diffusion in the doped $\mathrm{YZrON}$ (see also a typical depth profile in Fig. 1):

$$
\begin{aligned}
c(x, t) & =\frac{I\left({ }^{15} \mathrm{~N}\right)}{I\left({ }^{14} \mathrm{~N}\right)+I\left({ }^{15} \mathrm{~N}\right)} \\
& =\frac{Q}{\left(2 \pi\left(\Delta R_{\mathrm{P}}^{2}+2 D t\right)\right)^{0.5}} \exp \left(-\frac{\left(x-R_{\mathrm{P}}\right)^{2}}{2\left(\Delta R_{\mathrm{P}}^{2}+2 D t\right)}\right)
\end{aligned}
$$

Here, $Q$ is the implanted dose of ${ }^{15} \mathrm{~N}, \mathrm{I}\left({ }^{15} \mathrm{~N}\right)$ and $\mathrm{I}\left({ }^{14} \mathrm{~N}\right)$ are the measured SIMS isotope or cluster intensities, $R_{\mathrm{P}}$ is the implantation depth and $\Delta R_{\mathrm{P}}$ is the width of the initial Gauss profile. For the data evaluation of the annealed samples, the experimental obtained values of $\Delta R_{\mathrm{P}}$ and $R_{\mathrm{P}}$ were used, which were slightly higher than the value expected from the TRIM simulations $\left(R_{\text {P,TRIM }}=51 \mathrm{~nm} ; \Delta R_{\text {P,TRIM }}=46 \mathrm{~nm} ;\right.$ the TRIM calculations were performed assuming amorphous crystals).

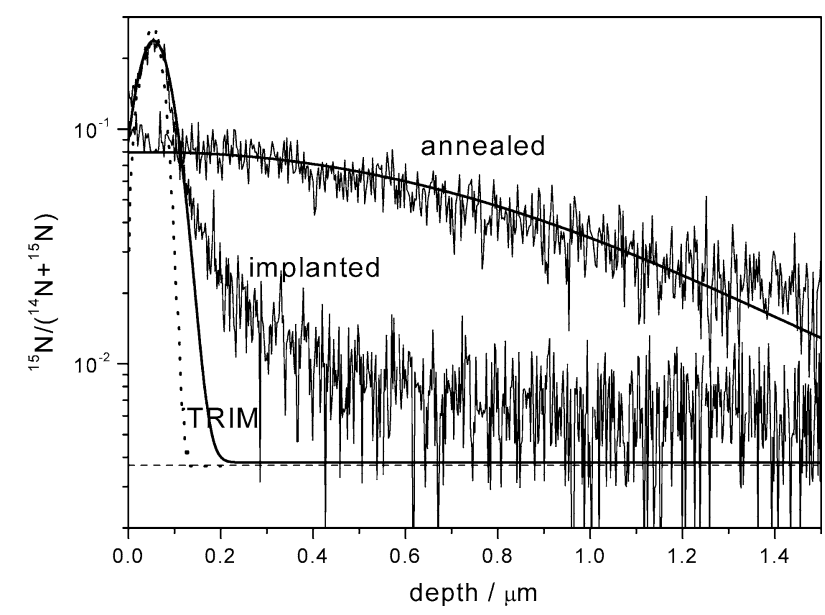

Fig. $1{ }^{15} \mathrm{~N}$ tracer diffusion profile for $\mathrm{YZrON}$ containing $1.55 \mathrm{wt} . \%$ nitrogen. Diffusion conditions: $46 \mathrm{~min}$ at $859 \mathrm{~K}$. The results of fits according to eqn. (3) are also shown. At high sample depth, the natural ${ }^{15} \mathrm{~N}$ content of $0.367 \%$ is approached (dashed line). Also shown is the result of a simulation using the program code TRIM ${ }^{11}$ (dotted curve). 


\section{Results and discussion}

\section{Nitrogen diffusion}

Nitrogen diffusion profiles (Fig. 1) are well described by eqn. (3) both in the initial (implanted) state as well as after diffusion annealing. For evaluation of the SIMS profiles of the diffused samples according to eqn. (3), we took the width $\left(\Delta R_{\mathrm{P}, \mathrm{SIMS}}=110 \mathrm{~nm}\right)$ and implantation depth $\left(R_{\mathrm{P}, \mathrm{SIMS}}=49\right.$ $\mathrm{nm})$ from the experimental SIMS profile of the implanted sample. The implantation profiles in Fig. 1 shows a Gaussian shape with a long tail at high profile depth, which is due to ion channelling. ${ }^{13}$ At a sample depth above $1000 \mathrm{~nm}$, the diffusion profile approaches the natural isotopic abundance of ${ }^{15} \mathrm{~N}$ (0.00367), proving that the mass signals chosen are purely representative for the nitrogen isotopes and not affected by impurities, like silicon or others.

The nitrogen diffusion coefficient has a constant slope when plotting $\ln D\left({ }^{15} \mathrm{~N}\right)$ vs. $1 / T$ leading to an activation enthalpy of about $2.1 \mathrm{eV}$ and a preexponential value of $0.8 \mathrm{~cm}^{2} \mathrm{~s}^{-1}$ (Fig. 2 and eqn. (4).

$$
D\left({ }^{15} \mathrm{~N}\right)=0.8 \times \mathrm{e}^{2.1 \mathrm{eV} / k T} \mathrm{~cm}^{2} \mathrm{~s}^{-1}
$$

The error in $\Delta H$ is $\pm 0.2 \mathrm{eV}$ while the error in $D_{0}$ corresponds to $\ln D_{0}=-0.22 \pm 2.1$.

These values of $\Delta H$ and $D_{0}$ are the same for samples containing different amounts of nitrogen. When comparing to an extrapolation of the data reported in refs. 9 and 10 measured at higher temperatures (between 1300 and $1500^{\circ} \mathrm{C}$ ) from the investigation of the nitrogen uptake into tetragonal zirconia, it is remarkable that the diffusivity values agree fairly well. The activation enthalpy obtained in the present work is only slightly higher than the values reported in the references. Moreover, the diffusivities obtained here compared with the oxygen and cation diffusion in YSZ without nitrogen, show that the nitrogen diffusion is slower than the oxygen diffusion by four orders of magnitude (see ref. 15 and similar values in ref. 16) but still many orders of magnitude faster than cation diffusion in stabilised zirconias. ${ }^{14}$

When comparing the nitrogen diffusion of samples containing 1.32 and $1.55 \mathrm{wt} \%$ of nitrogen, the difference in nitrogen diffusion is almost negligible, despite that the anion vacancy content should be increased and also the conductivity is

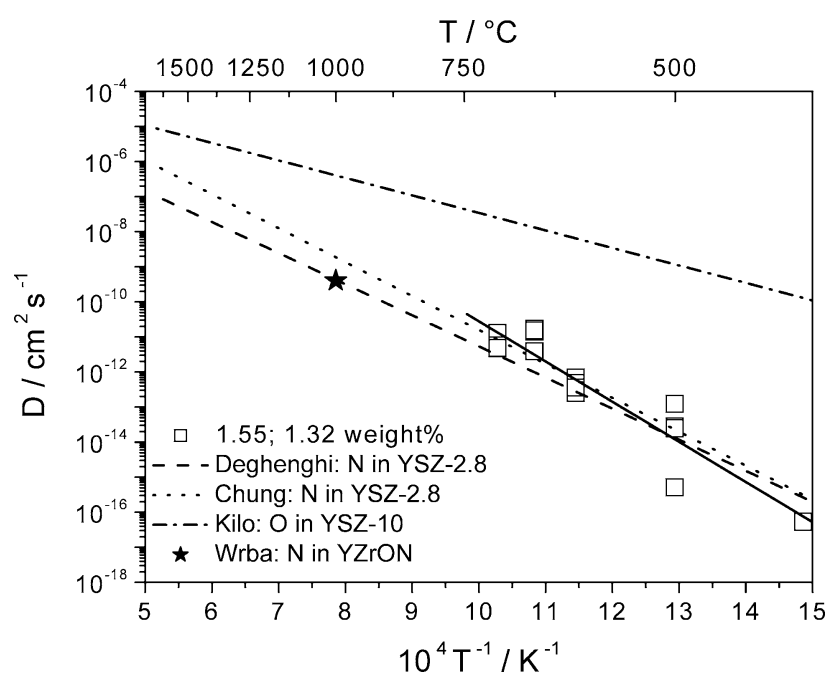

Fig. 2 Arrhenius plot of experimental nitrogen diffusivities in nitrogen doped yttria stabilised zirconia. Also shown are values obtained by extrapolation of the nitrogen uptake in YSZ (Deghenghi et al., ${ }^{9}$ and Chung et $a l^{10}$ ) and for the self-diffusion of $\mathrm{O}$ in YSZ (Kilo et $a l^{15}$ ) as well as one value of the self-diffusion in nitrided YSZ $\left(\mathrm{Wrba}^{18}\right)$. Straight line: result of a fit of our experimental data, leading to an activation enthalpy of $2.1 \mathrm{eV}$ and a preexponential factor of $0.8 \mathrm{~cm}^{2} \mathrm{~s}^{-1}$ increased significantly for these samples. According to eqn. (1), one would have expected the nitrogen diffusion to be increased with increasing nitrogen content. It is nevertheless still not clear how the nitrogen is distributed in the oxonitride phase: are the nitrogen anions really randomly distributed on the anion lattice, or are they somehow ordered, e.g. in microdomains, as was suggested by Lerch. ${ }^{8}$ In this case, diffusion experiments and conductivity experiments cannot be directly compared since an electrical field might affect the stability of the microdomains.

The activation entropy $\Delta S$ of diffusion, as derived from the preexponential factor of $0.8 \mathrm{~cm}^{2} \mathrm{~s}^{-1}$, was calculated according to eqn. $(5):^{17}$

$$
\Delta S / k_{\mathrm{B}}=\ln \frac{6 D_{0}}{a^{2} f \nu_{0}}
$$

Taking $a=5.14 \AA$ being the lattice constant of $\mathrm{YZrON},{ }^{18}$ $f=0.65$ being the correlation factor, and $\nu_{0}=1.3 \times 10^{13}$ $\mathrm{s}^{-1}$ being the Debye frequency, ${ }^{17}$ one gets a value of $5 k_{\mathrm{B}}$. For migration along vacancies, one would expect a value of $3 k_{\mathrm{B}}$; the obtained value of $5 k_{\mathrm{B}}$ is, especially when considering the relatively large experimental error in measuring $D_{0}$, still in agreement with the assumption of a migration along free vacancies. In particular, if there was a migration along clusters, the activation entropy should be strongly affected. This means that there is no strong evidence for the diffusion of nitrogen to go along microdomains. The diffusion of nitrogen seems to occur straight along the anion vacancy lattice.

\section{Nitrogen surface exchange}

The nitrogen surface exchange properties were studied at $800{ }^{\circ} \mathrm{C}$ under an atmosphere of 200 mbar ${ }^{15} \mathrm{~N}_{2}$ starting from YZrON samples containing $1.55 \%$ nitrogen. After $30 \mathrm{~min}$ annealing time, which corresponds to a bulk diffusion length of $150 \mu \mathrm{m}$ according to the Arrhenius fit given above in eqn. (4), the samples were nearly transparent. Since it remains unclear whether this is due to a loss of nitrogen or due to some electronic effects, the exchange reactions have been repeated by heating samples in a bed of carbon powder, in a bed of titanium powder, and in a carbon crucible. Except for the titanium powder, all samples were still transparent after the experiment. After the measurements, the nitrogen content in the samples was measured using SIMS and the total signal for nitrogen was compared with calibrated samples. It was found to be 0.6 to $0.7 \%$ for all samples, meaning that there seems to be no significant loss of nitrogen. The samples have taken up some ${ }^{15} \mathrm{~N}$, as can be seen from Fig. 3, where the

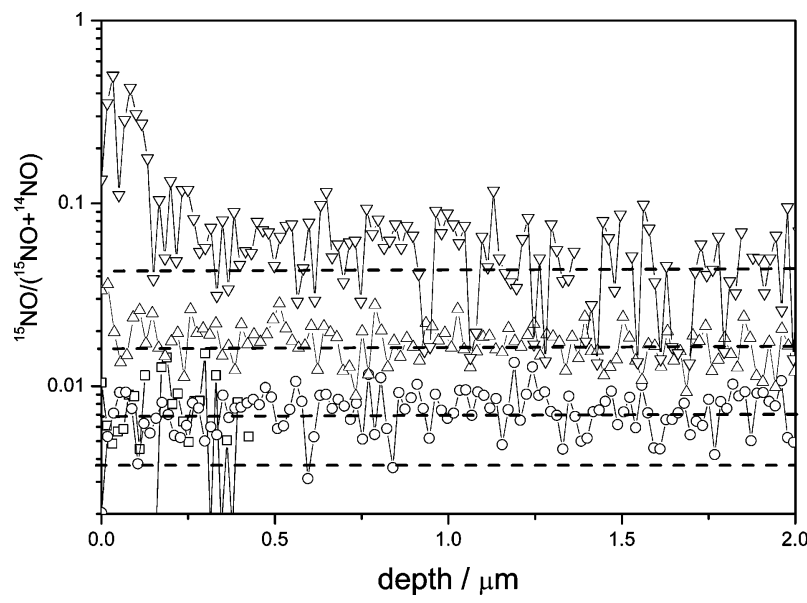

Fig. 3 Nitrogen surface exchange profiles for samples heated for 30 min at $800^{\circ} \mathrm{C}$. $\square$ : as received, $\bigcirc$ : annealed under nitrogen, $\triangle$ : annealed under carbon powder, $\nabla:$ annealed in a titanium powder bed. 
concentration of ${ }^{15} \mathrm{~N}$ is significantly higher than the natural abundance of nitrogen, but nevertheless, the amount is still low. The highest nitrogen exchange was induced for the sample heated in a titanium bed, inducing a low oxygen partial pressure, the lowest for the sample heated in pure nitrogen. The nitrogen surface exchange coefficient can be calculated using eqn. (6). ${ }^{19}$

$$
\begin{aligned}
c(x, t)-c_{0}= & \left(c_{\mathrm{g}}-c_{0}\right) \\
\times & \left(\operatorname{erfc} \frac{x}{(4 D t)^{0.5}}-\exp \left(h x+h^{2} D_{0} t\right)\right. \\
& \left.\quad \times \operatorname{erfc}\left(\frac{x}{(4 D t)^{0.5}}+h(D t)^{0.5}\right)\right)
\end{aligned}
$$

Here, $c_{0}$ and $c_{\mathrm{g}}$ are the natural abundance and the initial concentration of the tracer isotope, respectively $\left(c_{0}=0.00367\right.$, $\left.c_{\mathrm{g}}=0.98\right), k(k=h / D)$ is the rate constant for the surface exchange ${ }^{19}$ and $t$ is the diffusion time.

Surface exchange coefficients $k$ were calculated from eqn. (6) by taking the surface concentrations of ${ }^{15} \mathrm{~N}$, i.e. the value for $x=0$ together with the diffusion coefficient from eqn. (4) (and assumed to be independent of the oxygen partial pressure). From a plot of the $k$ values against the oxygen partial pressures (assuming the equilibrium partial pressures of the element/oxygen-systems, taken from ref. 20) in Fig. 4, the exchange exponent $n=-0.034$ can be deduced. For the oxygen surface exchange in perovskites and ionic conductors, values of the exchange exponent $n$ between 0.3 and 0.8 have been reported, ${ }^{21}$ and a theoretical dependency on the oxygen vacancy concentration according to $n \sim\left[\mathrm{V}_{\mathrm{O}}^{2 *}\right]^{2 / 3}$ has been postulated. ${ }^{22}$ The exchange exponent should be sensitive to the concentration of free anion vacancies at the surface. The absolute $n$ value obtained here is much smaller than observed for the oxygen exchange, but not equal to zero. A direct comparison to the oxygen exchange is only possible for the equivalent nitrogen exchange exponent, which needs to be measured, but it seems to be the case that the surface exchange reactions of nitrogen and oxygen on $\mathrm{YZrON}$ are not strongly correlated. Since the value of $n$ is negative, the two exchange reactions are concurring reactions. Until now, the nitrogen surface exchange reaction has not been investigated. For the oxygen surface exchange in oxides, it is widely known that the exchange reaction can be seriously enhanced or suppressed on changing the atmosphere and the exchange conditions. ${ }^{22,23}$ It is generally found that the surface exchange is lowest for nearly perfect surfaces, as can be obtained by freshly cleaved single crystals. ${ }^{24}$ Adding some impurities into the gas, e.g. water or carbon oxides, or starting with labelled oxygencontaining gases enhanced the surface exchange as well, as

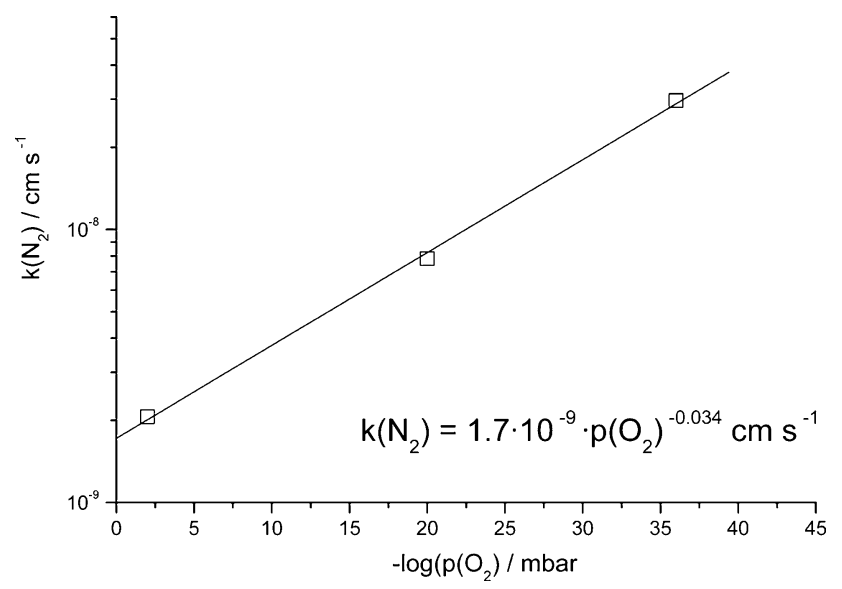

Fig. 4 Nitrogen surface exchange coefficient as a function of the oxygen partial pressure. does the formation of some active layers on the surface. ${ }^{23}$ The surface exchange reaction can be also greatly enhanced with physical methods like plasmas ${ }^{25}$ or ultraviolet light. ${ }^{26}$ It can be expected that similar processes take place also for the nitrogen surface exchange of nitrogen in nitrogen-containing materials. Further work is needed to check experimentally whether similar effects can be found here for the nitrogen surface exchange reaction. Also, it needs to be checked if the diffusion coefficients of both oxygen and nitrogen in $\mathrm{YZrON}$ are nitrogen- and oxygen-partial-pressure dependent, and how the dependencies are correlated with each other.

\section{Oxidation state of zirconium}

In the nitrogen gas exchange experiments, it was observed that the colour of the samples changed from black to white but there was still some remaining nitrogen. To check if the black colour is due to a change in the state of zirconium or not, we have measured XPS spectra of the nitrided and the graphiteannealed samples. The most likely species would be $\mathrm{Zr}^{3+}$, as could be expected from the formation of $\mathrm{ZrN}$, which would even increase the concentration of anion (oxygen) vacancies and the anion diffusivities:

$$
2 \mathrm{Zr}_{\mathrm{Zr}}^{x}+\mathrm{O}_{\mathrm{O}}^{x} \rightarrow 2 \mathrm{Zr}_{\mathrm{Zr}}^{\prime}+\mathrm{V}_{\mathrm{O}}^{2 \cdot}+\frac{1}{2} \mathrm{O}_{2}
$$

From the XPS spectrum (Fig. 5), one can observe that the $\mathrm{Zr3d}$ region of the nitrided sample containing $1.32 \mathrm{wt} . \%$ nitrogen consists only of one oxidation state of zirconium; there was no evidence of the formation of lower valent zirconium which would give rise to another peak doublet that can be found at a 0.8 to $1.0 \mathrm{eV}$ lower binding energy for $\mathrm{Zr}^{3+}$ or at even lower energies for $\mathrm{Zr}^{2+}$ and $\mathrm{Zr}^{0}{ }^{27}$ After annealing in graphite, the XPS spectrum of the $\mathrm{Zr} 3 \mathrm{~d}$ did not changed the structure; it was possible to fit the spectrum still assuming only the existence of one type of zirconium. This means that the black colour of the YZrON crystals is not due to the formation of lower valent zirconium. The formation of lowervalent yttrium, e.g. $\mathrm{Y}^{2+}$, is even less likely, since the reduction of $\mathrm{Y}^{3+}$ is less favourable than the reduction of $\mathrm{Zr}^{4+}$. The yttrium $3 \mathrm{~d}$ signal (not shown) did not change shape during the heat treatments, too.

\section{Summary}

Nitrogen migration properties in nitrogen-containing cubic yttria stabilised zirconia with different amounts of nitrogen

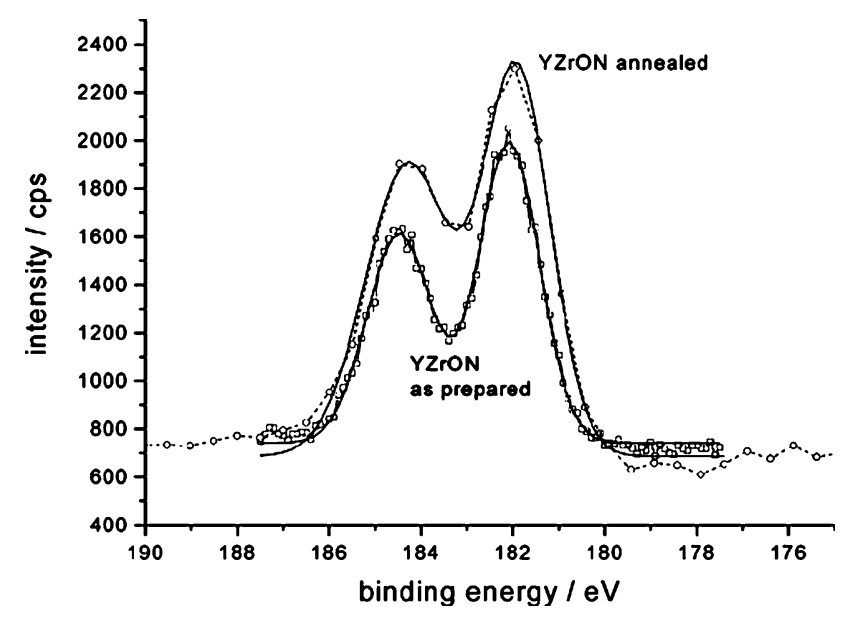

Fig. 5 XPS spectrum of the sample containing $1.32 \mathrm{wt} . \%$ nitrogen, as prepared and after annealing in nitrogen, along with a fit of the $\mathrm{Zr} 3 \mathrm{~d}$ $5 / 2$ and $\mathrm{Zr} 3 \mathrm{~d} 3 / 2$ peak doublet showing the existence of only one oxidation state of $\mathrm{Zr}$ in both cases. 
have been investigated by measuring the tracer diffusion of the stable isotope ${ }^{15} \mathrm{~N}$ :

(1) Experimentally, the nitrogen diffusion was shown to be independent of the nitrogen content for nitrided YSZ single crystals containing $10 \mathrm{~mol} \%$ yttria.

(2) The activation enthalpy of migration is around $2.1 \mathrm{eV}$, which is slightly higher than the value observed for nitrogen uptake into tetragonal zirconia.

(3) The nitrogen diffusion coefficients are slower by 4 orders of magnitude than the oxygen diffusivities obtained for similar pure, i.e. nitrogen-free YSZ.

(4) $\mathrm{YZrON}$ takes up nitrogen from the gas phase even at $800^{\circ} \mathrm{C}$, and the exchange reaction can be affected by the ambient conditions

(5) The oxygen partial pressure dependency of the surface exchange coefficient $k$ is small. $k$ decreases with increasing $p \mathrm{O}_{2}$, suggesting concurring surface reactions for the oxygen and nitrogen uptake from the gas phase.

\section{Acknowledgements}

The authors are thankful to the Deutsche Forschungsgemeinschaft for substantial financial support. We would like to thank Anissa Gunhold and Martin Frerichs, TU Clausthal, for measuring the XPS spectra. SIMS spectra were partially measured at École des Mines, Nancy/France, by Sylvain Weber.

\section{References}

1 , Key Engineering Materials: Zirconia Engineering Ceramics: Old Challenges-New Ideas, ed. E. H. Kisi, Trans Tech Publications Inc., Uetikon-Zürich, Switzerland, 1998, vol. 153-154.

2 Y.-B. Cheng and D. P. Thompson, J. Am. Ceram. Soc., 1993, 76, 683-688.

3 J. Wendel, M. Lerch and W. Laqua, J. Solid State Chem., 1999, 142, 163-167.
4 J. Wrba, M. Lerch and G. Müller, J. Mater. Sci. Lett., 2000, 19 107-109.

5 D. J. M. Bevan, J. Mohyla, K. S. Wallwork, H. J. Rossell and E. Schweda, Z. Anorg. Allg. Chem., 2002, 628, 1180-1186.

6 I. Molodetsky, A. Navrotsky, F. DiSalvo and M. Lerch, J. Mater. Res., 2000, 15, 2558-2570.

7 I. Molodetsky, A. Navrotsky, M. Lajavardi and A. Brune, Z. Phys. Chem., 1998, 207, 59-66.

8 M. Lerch, J. Mater. Sci. Lett., 1998, 17, 441-443.

9 G. Deghenghi, T.-J. Chung and V. Sergo, J. Am. Ceram. Soc., 2003, 86, 169-173.

10 T.-J. Chung, J.-S. Lee, D.-Y. Kim and H. Song, J. Am. Ceram. Soc., 1999, 82, 3193-3199.

11 J. Ziegler, http://www.srim.org.

12 P. Fielitz, M.-P. Macht, V. Naundorf and H. Wollenberger, Z. Metallkd., 1996, 87, 439-441.

13 H. Ryssel and I. Ruge, Ion Implantation, Wiley, Chichester, 1986

14 M. Kilo, M. A. Taylor, C. Argirusis, G. Borchardt, B. Lesage, S. Weber, S. Scherrer, M. Schroeder and M. Martin, J. Appl. Phys., 2003, 94, 7547-7552.

15 M. Kilo, C. Argirusis, G. Borchardt and R. A. Jackson, Phys. Chem. Chem. Phys., 2003, 5, 2219-2224.

16 P. S. Manning, J. D. Sirman, R. A. de Souza and J. A. Kilner, Solid State Ionics, 1997, 100, 1.

17 J. D. Solier, I. Cachadiña and A. Dominguez-Rodriguez, Phys. Rev., 1993, B45, 3704-3712.

18 J. Wrba, PhD Thesis, Würzburg University, 1998

19 R. J. Chater, S. Carter, J. A. Kilner and B. C. H. Steele, Solid State Ionics, 1992, 53-56, 859-865.

20 D. Gaskell, Introduction to Metallurgical Thermodynamics, McGraw-Hill, Washington DC, 1973.

21 J. A. Lane, S. Benson, D. Waller and J. A. Kilner, Solid State Ionics, 1999, 121, 201-208.

22 J. A. Kilner, R. A. De Souza and I. C. Fullarton, Solid State Ionics, 1996, 86-88, 703-710.

23 M. Leonhardt, R. A. De Souza, J. Claus and J. Maier, J. Electrochem. Soc., 2002, 149, J19-J26.

24 J. Claus, G. Borchardt, S. Weber and S. Scherrer, Z. Phys. Chem., 1998, 206, 49-72.

25 M. Rohnke, J. Janek, J. A. Kilner and R. J. Chater, Solid State Ionics, submitted.

26 R. Merkle and J. Maier, Phys. Chem. Chem. Phys., 2002, 4, 4140-4148.

27 M. Kilo, M. Hund, G. Sauer, A. Wokaun and A. Baiker, J. Alloys Compd., 1996, 236, 137-150. 